University of Zurich

Department of Economics

Working Paper Series

ISSN 1664-7041 (print)

ISSN1664-705X(online)

Working Paper No. 7

\title{
Social Comparison in the Workplace: Evidence from a Field Experiment
}

Alain Cohn, Ernst Fehr, Benedikt Herrmann, Frédéric Schneider

March 2011 


\title{
Social Comparison in the Workplace: Evidence from a Field Experiment
}

\section{Alain Cohn, Ernst Fehr, Benedikt Herrmann, Frédéric Schneider ${ }^{*}$}

\section{February 2011}

\begin{abstract}
We conducted a randomized field experiment to examine how workers respond to wage cuts, and whether their response depends on the wages paid to coworkers. Workers were assigned to teams of two, performed identical individual tasks, and received the same performance-independent hourly wage. Cutting both team members' wages caused a substantial decrease in performance. When only one team member's wage was cut, the performance decrease for the workers who received the cut was more than twice as large as the individual performance decrease when both workers' wages were cut. This finding indicates that social comparison processes among workers affect effort provision because the only difference between the two wage cut conditions is the other team member's wage level. In contrast, workers whose wage was not cut but who witnessed their team member's pay being cut displayed no change in performance relative to the baseline treatment in which both workers' wages remained unchanged, indicating that social comparison exerts asymmetric effects on effort.
\end{abstract}

JEL classification: $\quad$ C93, J33, M53

Keywords: $\quad$ Compensation, Fairness, Field Experiment, Social Comparison

\footnotetext{
* Alain Cohn and Ernst Fehr: University of Zurich, Department of Economics, alain.cohn@econ.uzh.ch, ernst.fehr@econ.uzh.ch; Benedikt Herrmann: European Commission, Brussels, benedikt.herrmann @ nottingham.ac.uk; Frédéric Schneider: University of California, Berkeley, Department of Economics, frederic.schneider@berkeley.edu.
} 
Social comparison processes between workers play a potentially important role both within firms and in the labor market. They may affect firms' internal pay structure (Baron and Kreps 1999), employees' work morale (Bewley 1999, Greenberg, Ashton-James and Ashkanasy 2007, Krueger and Mas 2004, Mas 2008) and thus firms' labor demand, firm boundaries and firms' ability to change relative wages between workers (Camerer and Malmendier 2007), wage changes over time (Babcock and Loewenstein 1997, Falk, Fehr and Zehnder 2006, Mas 2006), and even the rate of unemployment (Akerlof and Yellen 1990). The hypothesis that social comparison processes and associated fairness concerns affect the labor market has a long history; it dates back at least to Marshall (1890), Slichter (1920), and Hicks (1932), and practitioners, such as William H. Davis, director of the National War Labor Board from 1942 to 1946, were also convinced that unjust inequalities in wages within a firm cause a "break down (of) morale, create individual dissatisfaction, encourage absenteeism, increase labor turnover and hamper production"(in Kochan and Barocci 1985, p.249).

Despite notable recent contributions to this topic (e.g., Card, Mas, Moretti and Saez 2010, Charness and Kuhn 2007, Clark, Masclet and Villeval 2010, Clark and Senik 2010, Falk and Knell 2004, Hennig-Schmidt, Rockenbach and Sadrieh 2010, Thöni and Gächter forthcoming), however, the evidence on the causal effects of social comparison on the behavior of labor market participants is still limited. Perhaps the most difficult problem is finding exogenous sources of wage variations that trigger social comparison processes associated with behavioral effects. It is often unclear in available field data, for example, whether wage inequalities between workers are the consequence or the cause of performance differences. To solve this problem, we conducted a randomized field experiment in a company which formed teams of two employees for a temporary promotion campaign. Both team members had identical individual tasks and were paid the same hourly wage during the first phase of the experiment. The workers' task was to sell promotional cards that permitted entrance to specific nightclubs and bars on specific dates, yielding a clean measure of each team members' performance in terms of the number of cards sold. The formation of teams of two with identical tasks and identical pay made it 
very plausible for the two team members to become natural comparison agents for each other, which set the stage for the second phase of the experiment.

The firm implemented three treatments in the second phase of the experiment. In the baseline treatment, the hourly wage was not changed relative to the first phase; in the general wage cut treatment the firm cut both team members' hourly wages by 25 percent; and in the unilateral wage cut treatment the firm cut only one team member's hourly wage by 25 percent. This design enables us to study social comparison effects by comparing the unilateral with the general wage cut treatment. In particular, if workers who received a wage cut behave differently in the unilateral wage cut treatment compared to the general wage cut treatment, social comparison processes play a role because the only difference between the two treatments is the other team member's wage. In addition, our design allows us to examine the general impact of wage cuts by comparing workers' effort in the general wage cut treatment with their effort in the baseline treatment. Finally, we can also study how those workers responded whose wage remained constant while that of their team member was cut.

We observe that a general wage cut reduced workers' performance by 15 percent relative to the baseline treatment, while those workers whose wages were lowered in the unilateral wage cut treatment reduced their performance by 34 percent, i.e., by more than twice as much. This result suggests that social comparison can have powerful and large effects on individual behavior - although all workers who suffered from a wage cut earned exactly the same wage, their performance was very different. Interestingly, workers whose wages were not cut in the unilateral wage cut treatment neither reduced nor increased their performance relative to the baseline treatment.

In view of the temporary nature of the firm's promotion campaign and the clear information to the employees that they were only hired for this campaign and that no future employment at this firm was possible, it seems very unlikely that reputation effects or repeated game effects can explain our result. It is thus plausible that the large performance reduction in the unilateral wage cut treatment was driven by workers' fairness assessments. The workers whose wage was cut in this treatment may have 
perceived their cut as much more unkind than a general wage cut. This interpretation is consistent with theories of intention based reciprocity (Dufwenberg and Kirchsteiger 2004, Falk and Fischbacher 2006, Rabin 1993) if the notion of kindness - which is key in these models - includes payoff comparisons across different workers. In addition, we show in this paper that the theory of inequity aversion (Fehr and Schmidt 1999), which assumes that payoff comparisons between agents enter their utility functions, predicts all three empirical regularities: the reduction of performance in the general wage cut treatment, the stronger reduction of performance in the unilateral wage cut treatment for the workers whose wage was cut, and the absence of any change in performance for the workers whose wage was not cut in the unilateral wage cut treatment. Thus, inequity aversion may also have played a role in workers' behavior.

Our paper is related to field studies that report a negative correlation between wage inequality within firms and workers' self-reported performance measures (Levine 1993, Pfeffer and Langton 1993). However, these observational data do not enable the researchers to establish the causal impact of wage dispersion on individual performance because causality could be reverse - it is possible that performance differences cause wage differences. Our findings are also consistent with recent survey results that indicate that university employees' self-reported job satisfaction responds asymmetrically to information about their colleagues' wages (Card, Mas, Moretti and Saez 2010). Those below the median wage report a decrease in pay and job satisfaction and a higher willingness to search for a new job, while the satisfaction and the willingness to search for those above the median wage remains unchanged. This observation is in line with our asymmetric findings from the unilateral wage cut treatment - while the workers whose wage was cut responded strongly with a performance decrease, the workers whose wage was not cut did not respond at all. However, we believe that our study goes beyond the findings of Card et al. because we can demonstrate a causal impact of wage comparison on workers' actual performance behavior.

To cleanly identify social comparison effects, we deliberately implemented an experiment in which the workers faced neither explicit performance incentives nor reputation incentives. Our paper is therefore related to the literature on gift exchange in 
laboratory and field environments which examines the impact of wage variations on effort behavior in the absence of explicit and implicit performance incentives (Brandts and Charness 2004, Charness 2000, Charness, Frechette and Kagel 2004, Cohn, Fehr and Goette 2009, Cooper and Kagel 2009, Fehr and Falk 1999, Fehr, Kirchsteiger and Riedl 1993, Gneezy and List 2006, Hannan, Kagel and Moser 2002, Kube, Maréchal and Puppe 2010a, Kube, Maréchal and Puppe 2010b, List 2006). These papers, however, do not examine the effect of wage comparisons across workers on effort behavior because they focus on bilateral gift exchanges between workers and firms in the absence of horizontal social comparisons between workers.

A small number of recent laboratory studies examine the role of social comparison information on workers' effort. Charness and Kuhn (2007) conducted a laboratory gift exchange experiment with one principal and two agents who differed in their effort productivity. They report that social comparison information about the other worker's wage does not influence effort. Thöni and Gächter (forthcoming) implemented a similar treatment in which the laboratory workers did not differ in productivity. They find that wage comparison information reduces a subject's effort somewhat if the other worker earns considerably more (i.e., twice as much). Finally, Clark, Masclet and Villeval (2010) report results from a bilateral gift exchange experiment (with identical effort productivity across different firm-worker pairs) that indicates that workers' ordinal wage rank in an experimentally constructed reference group has a positive impact on their effort. These studies thus suggest that wage comparison information affects workers' effort in lab settings in which the laboratory workers know they have identical effort productivities. However, we do not know of any study that shows that wage comparison has a causal effect on work performance in a natural setting where subjects are unaware of being part of an experiment. In view of the fact that some economists have raised skepticism regarding the generalizability of results from the lab to the field (for a discussion, see Falk and Heckman 2009, List 2008), this information is important.

Our paper is also related to the literature on reference point effects on labor supply such as Abeler et al. (forthcoming), Camerer et al. (1997), Farber (2005), Fehr and Goette (2007), Mas (2006), and Oettinger (1999) - because the other team member's wage may be 
considered as a salient reference point that is used for assessing the fairness of the own wage. The reference point in these papers, however, is not socially determined by the coworkers' wage and thus there is no social comparison effect on labor supply. ${ }^{1}$

We believe that our evidence also provides insights into the performance effects of general wage cuts. Previous evidence on this question is largely derived from interview and survey studies (Agell and Lundborg 1995, Bewley 1998, Blinder and Choi 1990, Campbell and Kamlani 1997), and based on employers' counterfactual beliefs about the potential effects of wage cuts. One reason for the absence of clean behavioral evidence on the effort effects of wage cuts is that finding exogenous wage variations involving nominal pay cuts is very difficult. In addition, because employers often fear that wage cuts will have detrimental effects on work morale, they typically do not allow the implementation of experiments with random assignment of workers to different wage cut treatments. Fortunately, we could convince "our" employer to assign workers to the baseline and the two wage cut treatments randomly, enabling us to show that a general cut in the hourly wage reduces workers' performance. This evidence is related to the findings of Kube, Maréchal and Puppe (2010b), who show that if workers are hired for a projected hourly wage of $€ 15$ but only receive $€ 10$ when they arrive at work, performance is lower compared to when they receive the projected $€ 15$. Among other aspects, the Kube, Maréchal and Puppe study differs from ours because (i) they did not implement work teams and could thus not study wage comparison effects, and (ii) they did not cut wages in an ongoing employment relation.

Our results may help understand important economic phenomena. Akerlof and Yellen (1990) have shown that social comparison processes may lead to involuntary unemployment. Furthermore, such processes may be a major reason for the absence of two-tier labor markets. In principle, two-tier labor markets could be a method for lowering wages by paying lower wages to new hires who perform the same tasks as the incumbent workers. Airlines such as American Airlines, Delta, or Northwest introduced two-tier wage

\footnotetext{
${ }^{1}$ Mas (2006) has a slightly different focus compared to the other articles mentioned in this paragraph. While Mas (2006) focuses on police officers' performance following a final offer arbitration that led to disappointing wage increases, the other papers examine the potential relevance of loss averse preferences on labor supply.
} 
systems in the 1980s. These wage systems were, however, abolished in the 1990 s because they seem to have led to worker resentment and high turnover (Card 1997). ${ }^{2}$ Social comparison effects could also be a reason for firms' inefficient outsourcing decisions. Outsourcing part of the work force is likely to reduce social comparison between the incumbent and outsourced workers which may make reducing wages easier. Due to savings in wage costs, outsourcing certain firm activities may be profitable, even if it causes an increase in other cost components. As a final example, social comparison effects may also cause a reduction in pay inequalities within the firm which may be associated with smaller pecuniary performance incentives. Frank (1984), for instance, shows that automobile and real estate salespersons were paid less than their marginal product, that is, their commission schemes were flatter than they should have been in the absence of social comparison. Taken together, these examples suggest that social comparison among workers may have important implications for labor markets.

The remainder of this paper is organized as follows. The next section describes the economic environment in which the experiment took place. Section II presents our experimental design and Section III discusses various theories that predict social comparison effects. Section IV describes our estimation strategy and presents the empirical results. Section $\mathrm{V}$ concludes the paper.

\section{Experiment Environment}

We conducted the field experiment in collaboration with a German firm that sells a member card permitting entrance to specific bars and nightclubs. The firm ran a sales promotion in two big German cities. For this purpose, it hired new workers for a temporary promotion job. ${ }^{3}$ Hires were not aware that they were part of an experiment. They were employed to work two shifts each on two consecutive weekends - the first two shifts on Friday and Saturday evening of the first weekend, the third and fourth shift on Friday and

\footnotetext{
${ }^{2}$ Salpukas (1987) reports circumstantial evidence that two-tier wage systems in the airline industry "produced a resentful class of workers who in some cases are taking their hostility out on customers".

${ }^{3}$ To rule out potential influences of job applicants' past interactions with members of the firm, those job applicants who knew an employee of the firm's permanent staff were not hired.
} 
Saturday evening of the subsequent weekend. The workers knew that the promotion campaign was a temporary activity that would only take place on these two consecutive weekends. Because workers had no prospect of further employment at the firm, reputation incentives are unlikely to play a role in our setting.

To study social comparison effects, we proposed that the firm organizes its promotion work force in teams of two where both workers in the team had identical tasks and responsibilities. Before the first shift, the workers were invited to a training session during which they were made familiar with the objective and procedures of the promotion, trained how to approach potential customers, and provided with equipment and clothing. In this training session, workers were also randomly allocated to teams of two and randomly assigned to be either "worker 1 " or "worker 2 " in the team. The team composition was fixed for the entire employment period, making the coworker in a team a natural reference agent.

The workers' task was to sell promotional cards at a price of $5 €$ or in exchange for a customer's personal information that enabled the firm to contact him or her afterwards. The personal information was recorded in a database and used to invite the customer to join the company's nightlife web portal. The firm could thus verify ex post whether the information the workers provided was correct by contacting the customer. The workers were, however, not informed that the validity of their information was checked.

Each team was assigned to a fixed location which was either a shopping avenue or a large nightclub. ${ }^{4}$ Each of the two workers had to sell cards at different areas of the location in such a way that communication between the workers and joint selling activities were ruled out. A team leader who met the workers before and after the work shifts managed the teams. Team leaders supplied workers with promotional cards and assessed various characteristics of the location such as the number of club visitors (i.e., potential customers) or weather conditions. In addition, they visited the locations during the shifts in an unobtrusive way to check whether everything was going well. ${ }^{5}$ After the shifts, the team

\footnotetext{
${ }^{4}$ Working hours for shopping avenues were from $5 \mathrm{pm}$ to $8 \mathrm{pm}$ and for nightclubs from $11 \mathrm{pm}$ to $2 \mathrm{am}$.

${ }^{5}$ Team leaders had to ensure, for example, that the workers did not run out of cards to sell.
} 
leaders collected the revenues, the customer information collected by the workers, and the unsold cards. Team leaders were permanent employees of the firm and each of them was responsible for two to three teams during a shift. They received a comprehensive set of instructions on how to communicate with the workers. In particular, they were instructed to treat all workers in the same manner and they were forbidden to motivate or rebuke particular workers.

\section{Experiment Design}

We implemented a difference-in-difference setup with a pre- and a post-intervention phase. The pre-intervention phase allows us to capture the workers' baseline performance and therefore to control for individual heterogeneity. This is important because many field experiments report substantial heterogeneity in workers' abilities and emphasize the importance of controlling for it (Fehr and Goette 2007, Mas and Moretti 2009, Shearer 2004).

In the pre-intervention phase, all workers were paid an hourly wage of $€ 12$. For the post-intervention phase, we randomly assigned teams to one of three treatments. In the unilateral wage cut treatment, denoted by HL, worker 2's hourly wage was cut by €3, while worker 1 continued to earn the previous hourly wage of $€ 12$. Treatment HL thus consists of two groups, that of low-wage workers (HL2) and that of high-wage workers (HL1). In the general wage cut treatment, denoted by LL, both worker 1 and worker 2 in a team suffered a wage cut of $€ 3$. In the baseline treatment, denoted by $\mathrm{HH}$, both worker 1 and worker 2 continued to earn the previous hourly wage of $€ 12$ (see Table [1] for a treatment overview). The team leaders informed the workers about the wages in the post-intervention phase at the beginning of the first shift on the second weekend. In the HL treatment, for example, they used the following phrase: "Worker 1 continues to earn $€ 12$ per hour while worker 2 receives $€ 9$ instead of $€ 12$ per hour. This was the manager's decision." Since we were interested in the effects of wage cuts, team leaders were instructed not to give any further explanations or rationalizations for the cut. 
[Table 1 here]

To maximize the statistical power of the experimental design, we stratified treatment assignment by city, location type, and gender. We arranged the work schedule so that workers from different treatments did not meet; furthermore, workers who knew each other were assigned to the same treatment. In addition, friends were always assigned to different teams to preclude friendship arrangements within teams. Furthermore, we exclusively formed same gender teams to avoid gender-related confounds. Importantly, workers were unaware that they were participating in an experiment to rule out experimenter demand effects.

\section{Hypotheses}

How do workers respond to wage cuts? And how does their response depend on the wages paid to their coworkers? With the standard assumption that workers only want to maximize their own material payoff, the prediction is straightforward: workers will not respond to a change in the hourly wage provided that the wage is independent of effort and there is no prospect for future employment at the firm, thereby eliminating reputation incentives. ${ }^{6}$ The self-interest model thus predicts no performance difference between the treatments.

If we assume, however, that workers are also motivated by fairness or reciprocity concerns, the predictions are different. Many social preference theories assume that workers compare their outcomes to fair reference outcomes in order to define measures of fairness or reciprocity (Bolton and Ockenfels 2000, Cox, Friedman and Gjerstad 2007, Dufwenberg and Kirchsteiger 2004, Falk and Fischbacher 2006, Fehr and Schmidt 1999,

\footnotetext{
${ }^{6}$ Due to the short-term nature of the employment contract, efficiency wage incentives in the spirit of Shapiro and Stiglitz (1984) cannot play a role in our experiment. According to this model, workers may respond to a wage cut with an effort reduction because workers lose less rent at the lower wage if they are fired. This model does not predict, however, that wage cuts reduce effort by more in the HL treatment than in the LL treatment because the model does not rely on any sort of social comparison or interdependence between workers. Moreover, we made it clear to the workers that the employment contract lasts for exactly two weekends, so there was no threat of firing.
} 
Rabin 1993). In other words, these theories typically rely in some form on assumptions about social comparisons. According to intention-based reciprocity approaches, for example, workers may view a wage cut as a hostile act by the firm, and may consequently reduce their effort. The workers may view cutting only one worker's wage in a team as even more hostile, and this may further amplify the effort reduction.

Outcome-based considerations of fairness based on the comparison between the actual wage and a fair reference wage may also affect workers' fairness concerns. The Fehr and Schmidt model of inequity aversion, for example, is based on this approach. It assumes that in addition to their own material payoff, agents also want to avoid payoff inequalities between themselves and others, and the aversion against disadvantageous inequality ("envy") is stronger than the aversion against advantageous inequality ("compassion"). We show in the appendix that the model generates the following hypotheses about performance changes from the pre- to post-intervention phase if workers are sufficiently inequity averse:

(H1) Workers in treatment LL decrease their performance after the wage cut relative to workers in treatment $\mathrm{HH}$.

(H2) Workers in treatment group HL2 decrease their performance after the wage cut more than those in treatment LL.

(H3) Workers in treatment group HL1 do not change their performance relative to the $\mathrm{HH}$ treatment after their coworkers suffer the wage cut.

The intuition for the first hypothesis is as follows. Payoff equality between the two workers exists if both workers put forward the same effort and receive the same wage. Payoff equality between the firm and a worker exists if the workers' material payoff (measured by wage minus effort cost) is equal to the firm's profit from that worker (measured by revenue minus wage). In the equilibrium of the $\mathrm{HH}$ treatment, both workers choose an identical effort level that equalizes the payoffs across all three parties. The wage is lower in the LL treatment than in $\mathrm{HH}$, implying that the firm would have a payoff advantage if workers put forward the same effort in $\mathrm{LL}$ as in $\mathrm{HH}$. After the wage cut, the two workers will therefore 
re-establish equality between themselves and the firm by reducing effort in the LL treatment.

Why does the worker 2 with low pay in HL provide even less effort than workers in LL? Suppose that worker HL1 - whose wage is not cut - provides the same effort as in $\mathrm{HH}$, and worker HL2 puts forward the same effort as in LL. Recall that the same effort as in LL renders worker HL2's material payoff equal to the firm's profit from this worker, but worker HL2 now suffers from envy with respect to worker HL1. By further reducing the effort (cost) below the level of the LL treatment worker HL2 can reduce the payoff disadvantage relative to worker HL1, but this also generates a payoff advantage relative to the firm. However, because envy looms larger than compassion, it is better for worker HL2 to reduce envy with regard to worker HL1 and accept the small compassion cost with regard to the firm. Worker 2's effort in treatment HL will thus be lower than in LL.

Why does worker HL1 provide the same effort as workers in HH? By increasing the effort above the $\mathrm{HH}$ level (i.e., by reducing the own material payoff), worker HL1 would reduce the payoff advantage with regard to worker $\mathrm{HL2}$, but this would also cause a payoff disadvantage with regard to the firm. Because envy looms larger than compassion, a higher effort than in $\mathrm{HH}$ would therefore imply a large envy cost with regard to the firm and a small compassion gain with regard to the worker. As a consequence, worker HL1 prefers providing the same effort as workers in the $\mathrm{HH}$ treatment.

Taken together, concerns for reciprocity or inequity aversion predict that (i) workers will respond to the general wage cut with an effort reduction and (ii) that the effort reduction will be even stronger in case of a unilateral wage cut. Note that the purpose of our experiment is to examine the relevance of social comparison processes in a field setting; it was not intended to discriminate between different models of fairness. 


\section{Estimation Strategy and Results}

Our sample consists of 96 workers in 48 teams. None of the workers quit after the wage cut. ${ }^{7}$ Table [2] shows that roughly three quarters of the workers were women and that their average age was slightly above 20. All but one of the workers were German citizens. On average, the workers exchanged 22.3 cards per shift and the customers provided personal information instead of paying $€ 5$ for the card in 97.9 percent of these exchanges. Since the firm verified the correctness of the customer information, we know that this information was wrong only in 2.2 percent of the cases.

\section{[Table 2 here]}

We balanced the treatments over cities, location types (i.e., street versus nightclub), and gender. The pre-intervention phase enables us to control for worker heterogeneity by including individual fixed effects into our regression. In addition, we are able to include a proxy for the demand potential for cards as a control variable. Recall that the team leaders visited "their" teams several times during a shift. These visits allowed them to assess the number of potential customers for each team and shift on a 5 -point scale $(-2=$ very low, $1=$ moderately low, 0 = normal, 1 = moderately high, 2 = very high). We use this assessment to control for potential variations in demand across teams, shifts, and treatments. Therefore, we also report a specification in which we control for demand potential. ${ }^{8}$

Workers could exert effort in two dimensions: quantity (cards sold) and quality (correctness of customer information). Because almost all customer information the workers provided was correct, a separate analysis of the quality dimension is not informative. We use the total number of "correct" exchanges as a measure of performance, i.e., we exclude those sales that were associated with wrong customer information from our performance measure. ${ }^{9}$ Using the balanced panel data structure, we estimate the

\footnotetext{
${ }^{7}$ Three workers became sick before any wage cut was announced and missed both post-intervention shifts. These workers were replaced by spare workers who were treated in exactly the same way as the replaced workers would have been treated. We exclude spare workers from the analysis, however.

${ }^{8}$ Note that we cannot reject the null hypothesis that demand was equally distributed across treatments $(p=$ 0.23 , Kruskal-Wallis test). However, controlling for demand potential enables a more precise estimate of the treatment effects. All p-values reported in this paper are two-sided.

${ }^{9}$ The empirical results do not change if we analyze quantity without adjusting for quality.
} 
following difference-in-difference regression model with each worker as a panel unit and each team as an independent observation:

$$
\log \left(y_{i k t}\right)=\alpha+\phi_{i}+\delta D_{k t}+\beta_{1} t+\beta_{2}\left(L L_{i} \times t\right)+\beta_{3}\left(H L 1_{i} \times t\right)+\beta_{4}\left(H L 2_{i} \times t\right)+\epsilon_{i k t} .
$$

$\log \left(\mathrm{y}_{\mathrm{ikt}}\right)$ denotes the logarithm of the average performance of worker $i$ in team $k$ and weekend $t$. The constant $\alpha$ captures average pre-intervention performance, $\phi_{\mathrm{i}}$ represents individual fixed effects, $D_{k t}$ controls for differences in demand potential, and $\mathrm{t}$ is a dummy variable that equals 1 if the observation is from the post-intervention phase and zero otherwise. The coefficient of the variable $t$ thus measures the change in performance in the post-intervention phase relative to the average pre-intervention performance, and the coefficients of the three interaction terms $L L_{i} \times \mathrm{t}, H L 1_{i} \times t$, and $H L 2_{i} \times t$ measure the treatment effects relative to the omitted control treatment $\mathrm{HH}$. These coefficients are our difference-in-difference estimators of interest, as they capture the differences across treatments (relative to the control treatment $\mathrm{HH}$ ) in the performance change between preand post-intervention phase. Finally, $\epsilon_{\mathrm{ikt}}$ is the idiosyncratic error term, which we allow to be clustered over teams. Because workers were always assigned to the same location, individual fixed effects not only capture time invariant differences across workers but also location-specific factors. As expected, these fixed effects are significant ( $p<0.01$, F-test).

Based on the estimation strategy described above, we can report the following result with regard to hypothesis $\mathrm{H} 1$ which involves a comparison between the general wage cut and the baseline treatment:

Result 1: A general wage cut causes a decrease in performance.

We illustrate this result in Figure 1, which presents the performance changes from pre- to post-intervention phase by treatment in percent of the pre-intervention average. Panel (H1) shows that performance in control treatment $\mathrm{HH}$ increased insignificantly by 8 percent, possibly due to learning effects ( $p=0.58$, Wilcoxon Signed Rank). In contrast, performance in treatment LL decreased after the wage cut, but without further controls, this decrease is not significantly different from treatment $\mathrm{HH}(p=0.37$, Mann-Whitney $U)$. 
We therefore turn to the regression results which are displayed in Table 3. The first column represents the model above without controlling for demand potential, whereas we control for demand in the second column. ${ }^{10}$ The coefficient of demand is highly significant $(p<$ $0.01, \mathrm{t}$-test) and has the expected sign: the more potential customers were present at a location, the more cards the workers could sell. Moreover, the adjusted $\mathrm{R}^{2}$ increases substantially if we include the demand variable in the regression. Overall, these facts indicate that the number of potential customers is an important control variable that needs to be included in the regression.

The coefficient on "LL x Post-intervention" has a negative sign in both specifications reported in Table 3. If we control for demand potential, performance drops by roughly 15 percent compared to the control treatment $\mathrm{HH}$ which constitutes a substantial and significant ( $p=0.07$, t-Test) performance decrease. ${ }^{11}$

Next we turn to the test of hypothesis $\mathrm{H} 2$, which involves a comparison between the unilateral and the general wage cut treatment:

Result 2: A unilateral wage cut causes a much stronger decrease in performance than a general wage cut.

Support for Result 2 comes from Panel $(\mathrm{H} 2)$ of Figure 1 and Table 3. Although workers in treatment HL2 suffered the same monetary loss as workers in treatment $L L$, their drop in performance was more than double. This difference is already significant in the absence of further controls ( $p<0.05$, Mann-Whitney test). In addition, workers in HL2 also reduced their performance compared to their coworkers in HL1 who did not suffer the pay cut $(p<$ 0.01, Wilcoxon Signed Rank). Finally, the regressions in Table 3 indicate that the unilateral wage cut reduced HL2 workers' performance by 31 to 34 percent compared to control

\footnotetext{
${ }^{10}$ When demand potential is included in the regression, the number of observations decreases by 10 because the demand measure is missing for some shifts. The team leaders forgot to collect this information in these cases.

${ }^{11}$ As mentioned earlier, we routinely report two-sided p-values in this paper. However, hypotheses $\mathrm{H} 1$ and $\mathrm{H} 2$ are directional hypotheses, justifying the use of one-sided tests.
} 
treatment $\mathrm{HH}(\mathrm{p}<0.01$, t-test), a reduction about 20 percentage points larger than that in treatment $L L(p<0.01$, Wald test).

With regard to hypothesis $\mathrm{H} 3$, which involves a comparison between the unilateral wage cut condition and the baseline, we report the following result:

Result 3: A unilateral wage cut has no effect on the team members whose wage is not cut.

First support for Result 3 comes from Panel H3 in Figure 1. The panel shows that HL1 workers display almost the same performance change between the pre- and the postintervention phase as workers in the $\mathrm{HH}$ treatment $(p=0.37$, Mann-Whitney $U)$. In addition, both regression estimates of "HL1 x Post-intervention" in Table [3] confirm the finding that workers in treatment HL1 did not perform differently than those in the $\mathrm{HH}$ treatment $(p=0.72$ and $p=0.87$, t-test). Thus, performing the same task but earning more than one's coworker is not associated with higher effort.

[Figure 1 here]

[Table 3 here]

\section{Conclusion}

This paper reports evidence from a randomized field experiment on the behavioral effects of wage cuts and whether these effects depend on the wages paid to coworkers. We collaborated with a firm that temporarily hired workers for a sales promotion. The firm formed teams of two, and the workers in a team had identical individual tasks. Team members were paid the same hourly wage in the pre-intervention phase of the experiment. We subsequently implemented three treatments that enabled us to examine social comparison effects and the effects of wage cuts on performance. We find that cutting both team members' wages by 25 percent caused a decrease in performance by 15 percent relative to the baseline. In contrast, cutting only one team member's wage by 25 percent 
decreased the affected worker's performance by 34 percent, i.e., by more than twice as much as in the case of a general wage cut, even though pay levels and the size of the pay cuts were identical in both treatments. The unilateral wage cut had asymmetric effects on team members, that is, those workers whose wage was not cut neither decreased nor increased performance relative to the baseline.

Our results provide evidence on the causal effects of (i) general wage cuts and (ii) social comparison between workers on effort. Previous evidence on general wage cuts is largely based on interview and survey studies which rely on the employers' counterfactual beliefs about how workers would respond to wage cuts. Direct behavioral evidence on the causal effects of general wage cuts, however, is very rare. The notion that workers compare their wages relative to others and adjust their effort accordingly has also rarely been subjected to empirical tests in the field, even though it may have important consequences for a wide range of economic issues. It may induce employers to compress the wage distribution across workers, and, as demonstrated in Akerlof and Yellen (1990), social comparison effects may lead to involuntary unemployment. The key assumption in this model is that workers withdraw effort when their wage falls short of a "fair" wage that is partly dependent on coworkers' wages because of social comparison processes. These processes thus provide a rationale for firms to pay efficiency wages to the low-wageworkers. In this context it is also worthwhile to point out that other efficiency wage models such as the shirking model of Shapiro and Stiglitz (1984) cannot explain our results because their model does not predict that responses to wage cuts depend on coworkers' wages.

Social comparison processes may also be an important reason for firms' reluctance to implement two-tier wage systems. Two-tier wages systems seem to trigger considerable opposition from the workers and rarely persist once introduced (Card 1997, Krueger and Mas 2004). Our results indicate that these phenomena may be due to social comparison processes that are caused by unequal pay for equally skilled workers who perform the same tasks.

Finally, social comparison may also be an important determinant of firm boundaries. For example, the success of a merger of different firms may strongly depend on whether 
workers compare their wages to those of the coworkers in the same firm (Bartling and von Siemens 2009, Nickerson and Zenger 2008). This is because a merger may change the set of reference agents, implying that after the merger some of the incumbent workers may earn less than their new colleagues and thus reduce effort accordingly. Kole and Lehn (2000) report circumstantial evidence that U.S. Airways encountered unexpectedly high labor costs after taking over Piedmont Aviation because the former Piedmont workers threatened to strike if they did not receive the same generous wages as the U.S. Airways workers. Our findings thus support the view that firms boundaries may not only be driven by transaction costs or property rights concerns (Holmström and Roberts 1998), but that social comparison processes may also shape them. 


\section{Appendix: Prediction of workers' effort responses to wage changes}

To analyze how workers respond to wage cuts and how their response depends on the wages paid to their coworkers, we present a simple framework that mirrors the experiment environment. Consider a firm that hires a team of two identical workers who have to perform identical individual tasks. Assume first that each worker $i$ can generate a revenue for the firm by exerting costly effort $e_{i}$. The firm's payoff $\pi_{i}$ from worker $i$ is the worker's revenue $v e_{i}$ less her wage costs $w_{i}$ :

$$
\pi_{i}=v e_{i}-w_{i}
$$

with $i \in\{1,2\}, v>0, w_{i} \geq 0$ and non-negative effort $e_{i}$. For simplicity, we assume that minimal effort is given by $e_{i}=0$. Now assume that worker i's payoff is her wage less her effort costs $c e_{i}$ (measured below in money equivalent terms):

$$
x_{i}=w_{i}-c e_{i}
$$

where the constant $c$ obeys $0<c<v$. In our setup, wages are set independently of workers' effort and each worker knows her own wage and that of her coworker in the same team. In addition, workers have no prospect for future employment at the firm, implying that reputation or repeated game incentives cannot play a role.

With the standard assumption that only the own payoff enters workers' utility function, i.e. $U_{i}=x_{i}$, the analysis of their effort behavior is straightforward: because both explicit performance and reputation incentives are absent, a worker exerts the minimal effort, no matter what wage is offered to the worker and to the coworker in the team. The self-interest model thus predicts that neither wage cuts nor changes in coworkers' wages affect effort.

For tractability reasons, we use the model of inequity aversion developed by Fehr and Schmidt (1999) to study how social comparison processes and associated fairness concerns determine effort behavior. In their model, inequity averse workers dislike unequal payoffs. Thus, the utility function of worker $i$ is given by 


$$
U_{i}=x_{i}-\frac{\alpha}{2} \max \left\{\pi_{i}-x_{i}, 0\right\}-\frac{\beta}{2} \max \left\{x_{i}-\pi_{i}, 0\right\}-\frac{\alpha}{2} \max \left\{x_{j}-x_{i}, 0\right\}-\frac{\beta}{2} \max \left\{x_{i}-x_{j}, 0\right\}
$$

with $i \neq j$ and the assumptions $\beta \leq \alpha$ and $0 \leq \beta<1$. Worker i's utility is therefore the sum of her payoff and her disutility from both payoff differences between her and the firm, and her and her coworker $j$. The parameter $\alpha$ measures the extent to which workers suffers from receiving less than the firm or the coworker ("envy"), while $\beta$ measures the extent to which they suffer from receiving more than someone else ("compassion"). Hence, if both $\alpha$ and $\beta$ equal zero, workers only care about their own payoff and the model reduces to the standard economic model.

Because both explicit performance and reputation incentives are absent, the only incentive for inequity averse workers to exert more than minimal effort is to reduce payoff differences. Consider first payoff inequality between worker $i$ and the firm: ${ }^{12}$

$$
\left|x_{i}-\pi_{i}\right|=\left|2 w_{i}-(c+v) e_{i}\right|
$$

If worker $i$ provides the minimal effort (i.e., $e_{i}=0$ ), she creates a payoff advantage relative to the firm of $2 w_{i}$. Conversely, if she exerts more than minimal effort, she reduces this inequality by simultaneously increasing the firm's payoff and decreasing her own payoff; one unit of effort reduces the firm-worker inequality by $c+v$ units. Thus, worker i's effort that equalizes her and the firm's payoff is:

$$
e_{i}^{x_{i}=\pi_{i}}\left(w_{i}\right)=\frac{2}{c+v} w_{i} \equiv e_{i}^{F}
$$

where $e_{i}^{F}$ denotes the effort level that equalizes $x_{i}$ and $\pi_{i}$ for a given $w_{i}$. Consider now payoff inequality between worker $i$ and her coworker $j$ :

$$
\left|x_{i}-x_{j}\right|=\left|w_{i}-w_{j}-c\left(e_{i}-e_{j}\right)\right| .^{13}
$$

\footnotetext{
${ }^{12}$ We assume that workers exhibit narrow bracketing, i.e., they evaluate the fairness of their transaction with the firm in isolation from other determinants of the firm's profit. Rabin and Weizsäcker (2009) find that about 90 percent of subjects in their sample bracket narrowly and there is also field evidence suggesting that this feature of decision making has important consequences for investment decisions (Barberis, Huang and Thaler 2006) and labor supply (Fehr and Goette 2007).

${ }^{13}$ Without loss of generality, let $w_{i} \geq w_{j}$.
} 
Thus, by exerting effort, worker $i$ can also influence the payoff inequality relative to her coworker. In contrast to firm-worker inequality, however, one unit of effort reduces worker-worker inequality by only $c$ units because a worker's effort affects the firm's payoff but not the coworker's payoff. Consequently, worker i's effort that equalizes her and her coworker's payoff is:

$$
e_{i}^{x_{i}=x_{j}}\left(w_{i}, w_{j}, e_{j}\right)=e_{j}+\frac{w_{i}-w_{j}}{c} \equiv e_{i}^{C}\left(w_{i}, w_{j}, e_{j}\right)
$$

where $e_{i}^{C}$ denotes the effort level that equalizes $x_{i}$ and $x_{j}$ for a given level of $w_{i}, w_{j}$ and $e_{j}$. Before we proceed, it is useful to derive the non-pecuniary utility changes that are associated with changes in $e_{i}$. For example, if worker $i$ is better off than the firm $\left(x_{i} \geq \pi_{i}\right)$ and the coworker $\left(x_{i} \geq x_{j}\right)$, then the non-pecuniary utility gain that arises from an effort increase by one unit is given by

$$
\frac{\beta}{2}(c+v)+\frac{\beta}{2} c,
$$

where the first term measures the non-pecuniary utility gain that arises from a reduction of the firm-worker inequality, while the second term measures the non-pecuniary utility gain associated with a reduction in worker-worker inequality. Likewise, if worker $i$ is better off than the firm $\left(x_{i} \geq \pi_{i}\right)$ but worse off than the coworker $\left(x_{i}<x_{j}\right)$, then the non-pecuniary utility change that arises from worker i's effort increase is given by

$$
\frac{\beta}{2}(c+v)-\frac{\alpha}{2} c,
$$

where the first term measures the non-pecuniary utility gain that arises from a reduction of the firm-worker inequality, while the second term measures the non-pecuniary utility loss associated with a further increase in worker-worker inequality. Thus, the amount of effort that inequity averse workers provide depends strongly on the extent to which they care about payoff differences (i.e., on $\alpha$ and $\beta$ ). In view of this fact, the following statements will prove useful:

First, if worker $i$ does not suffer much from advantageous inequity (i.e., $\beta$ is below a certain threshold $\underline{\beta}$ ), she will never exert more than minimal effort even if both the firm 
and the coworker are worse off (i.e., even if $x_{i} \geq \pi_{i}$ and $x_{i} \geq x_{j}$ ). In this case, the nonpecuniary utility gain from reducing a payoff advantage relative to both the firm and the coworker, $\frac{\beta}{2}(c+v)+\frac{\beta}{2} c$, never outweighs the associated cost of effort $c$ :

$$
\frac{\beta}{2}(c+v)+\frac{\beta}{2} c<c \quad \Leftrightarrow \quad \beta<\frac{2 c}{2 c+v} \equiv \underline{\beta} .
$$

Second, we can derive a threshold value for $\alpha$, which we denote by $\bar{\alpha}$, such that if $\alpha$ is below the threshold $\bar{\alpha}$, the worker will always provide more than minimal effort, no matter how little effort the coworker exerts. In other words, if the worker does not suffer too much from disadvantageous inequity, she will always provide more than the minimal effort in case she has a payoff advantage relative to the firm. To see this in more detail, assume that $x_{i}>\pi_{i}$ and $x_{i} \leq x_{j}$. The non-pecuniary utility increase associated with an effort increase in this case is given by $\frac{\beta}{2}(c+v)-\frac{\alpha}{2} c$. If this utility gain exceeds the marginal cost of effort, we have:

$$
\frac{\beta}{2}(c+v)-\frac{\alpha}{2} c>c \quad \Leftrightarrow \quad \alpha<\beta \frac{c+v}{c}-2 \equiv \bar{\alpha}
$$

In this case, worker $i$ will increase effort as long as her payoff is higher than the firm's payoff, i.e., she will set $e_{i}=e_{i}^{F}$, but she will not exert effort above $e_{i}^{F}$. In fact, worker $i$ will never increase her effort above $e_{i}^{F}$ (which would imply $x_{i}<\pi_{i}$ ) even if this would allow her to reduce a payoff advantage relative to her coworker. This is because the non-penuniary utility change from a marginal increase in effort in case of $x_{i}<\pi_{i}$ and $x_{i}>x_{j}$ is given by

$$
-\frac{\alpha}{2}(c+v)+\frac{\beta}{2} c
$$

which is always negative because envy looms larger than compassion $(\alpha \geq \beta)$ and establishing payoff equality relative to the firm can be achieved more efficiently than relative to the coworker $(c+v>c)$.

A third type of situation arises if workers suffer much from both advantageous and disadvantageous inequity, i.e., if both $\alpha$ and $\beta$ are above their threshold levels. Then both workers will try to equalize worker-worker payoffs. To see this, assume that $e_{i}^{C} \leq e_{i}^{F}$ and 
$e_{j}^{C} \leq e_{j}^{F}{ }^{14}$ Suppose further that both provide effort levels $e_{i}^{C} \in\left[0, e_{i}^{F}\right]$ and $e_{j}^{C} \in\left[0, e_{j}^{F}\right]$, implying that both workers have equal payoffs. Because $\beta \geq \underline{\beta}$, each worker is not willing to individually decrease her effort because she would suffer too much from advantageous inequality relative to both the coworker and the firm. Similarly, because $\alpha<\bar{\alpha}$, each worker is not willing to individually raise her effort level because she would suffer too much from disadvantageous inequality with respect to her coworker, even if she can decrease advantageous inequality towards the firm. Thus, each pair of effort levels that equalizes worker-worker payoff is a Nash Equilibrium. As shown above, the difference between effort levels that equalize the workers' payoffs is determined by the wage differential: $e_{i}^{C}-e_{j}^{C}=$ $\frac{w_{i}-w_{j}}{c}$, implying that worker $i$, also provides more effort if she earns a higher wage than worker $j$. The boundaries of the continuum of Nash Equilibria are given by worker $j$ 's minimum effort level $e_{j}^{\text {min }}=0$ and worker i's maximum effort level $e_{i}^{F}=\frac{2}{c+v} w_{i}$.

\section{Description of Workers' Nash Equilibrium Strategies}

We are now able to characterize the three sets of Nash equilibrium strategies for worker $i$ and her coworker $j$ as a function of $\alpha$ and $\beta$ :
(i) $\beta<\beta$ :
$e_{i}^{*}=e_{j}^{*}=0$
(ii) $\quad \alpha<\bar{\alpha}, \beta \geq \underline{\beta}$ :
$e_{k}^{*}=e_{k}^{F}, k \in\{i, j\}$
(iii) $\alpha \geq \bar{\alpha}, \beta \geq \underline{\beta}$ :
$e_{i}^{*} \in\left[\frac{w_{i}-w_{j}}{c}, \frac{2}{c+v} w_{i}\right], e_{j}^{*}=e_{i}^{*}-\frac{w_{i}-w_{j}}{c}$

The effort implications of case (i) simply follow from the first statement above. If both workers have a low enough $(\beta<\underline{\beta})$, they will never increase their effort above the minimal level. The implications of case (ii) follow from the first and the second statement above: if $\beta$ exceeds the threshold value $\beta$, each workers' motive to avoid advantageous

\footnotetext{
${ }^{14}$ This assumption means that the difference in wages is not too big such that workers can equalize their payoffs within the boundaries of $\left[0, e_{i}^{F}\right]$ and $\left[0, e_{j}^{F}\right]$. Note that the effort levels that equalize workers' payoffs is given by $e_{i}^{C}-e_{j}^{C}=\frac{w_{i}-w_{j}}{c}$. Because workers cannot provide negative effort and because they never provide more than $e_{k}^{F}, k \in\{i, j\}$, it is in principle possible they cannot achieve equality between their payoffs with their effort choices. We deal with this case below (see next footnote).
} 
firm-worker inequality is sufficiently strong so that each of them equalizes $x_{i}$ and $\pi_{i}$; this holds even if the provision of $e_{k}^{F}$ would imply disadvantageous inequality relative to the coworker as long as $\alpha$ is lower than the threshold $\bar{\alpha}$. In case (iii), effort levels are chosen in such a way that both workers' payoffs are equal. Thus, any common effort level between 0 and $e^{F}$ is a Nash Equilibrium in case of equal wages, while workers generally provide different effort levels in order to equalize their payoffs in case of unequal wages. As a selection criterion in the case of a continuum of Nash Equilibria, we make use of the concept of the coalition-proof Nash equilibrium (Bernheim, Peleg and Whinston 1987). The Nash Equilibrium concept rules out individual deviations that are unprofitable. The coalition-proof Nash Equilibrium is more selective because it also rules out that subgroups coordinate and jointly deviate from equilibrium.

In case (iii), there are multiple Nash Equilibria if $\frac{w_{j}}{w_{i}} \geq \frac{v-c}{v+c} \cdot{ }^{15}$ In particular, there are many Nash equilibria in which the two workers could form a coalition and coordinate their effort provision so that both of them are better off. Two possible coalition proof Nash equilibria remain. Suppose first that workers care relatively little about advantageous inequality (i.e., a relatively low $\beta$, but one above $\underline{\beta}$ ), and, for simplicity, that wages are equal. If both workers provide a common intermediate effort level between 0 and $e_{k}^{F}$, this constitutes a Nash Equilibrium because an individual worker faces compassion cost with respect to both the firm and the coworker if she decreases her effort. Both workers can, however, improve their situation if they form a coalition and agree to provide zero effort. By collectively moving to a new common effort level, they avoid non-pecuniary utility losses arising from worker-worker inequality. This way they incur only compassion cost with

\footnotetext{
${ }^{15}$ The condition $\frac{w_{j}}{w_{i}} \geq \frac{v-c}{v+c}$ follows from the following considerations. Suppose that worker i's wage is high enough to induce effort $e_{i}^{F}=\frac{2}{c+v} w_{i}$ and that worker $j$ receives a lower wage. The effort $e_{j}$ that equalizes workers' payoffs is then given by $e_{j}^{C}=e_{i}-\frac{w_{i}-w_{j}}{c}=e_{i}^{F}-\frac{w_{i}-w_{j}}{c}=\frac{2}{c+v} w_{i}-\frac{w_{i}-w_{j}}{c}$. Thus, $e_{j}^{C} \geq 0$ iff $\frac{w_{j}}{w_{i}} \geq \frac{v-c}{v+c}$. Note that worker $j$ cannot equalize payoffs if $\frac{w_{j}}{w_{i}}<\frac{v-c}{v+c}$ holds. The reason for this is that $j$ 's wage is so small relative to i's wage that even at effort $0 j$ will earn less than $i$. In this "degenerate" case there is only one Nash equilibrium left in case (iii): $e_{i}^{*}=e_{i}^{F}=\frac{2}{c+v} w_{i}$ and $e_{j}^{*}=0$. In the following we always assume that $\frac{w_{j}}{w_{i}} \geq \frac{v-c}{v+c}$.
} 
respect to the firm, while saving on effort cost. Since this is true for every positive effort level, the only remaining equilibrium comprises zero effort by both workers.

The situation is only slightly more complicated in case that worker $i$ receives a higher wage than worker $j$. Then, the payoff equalization between the workers implies that worker $j$ will provide zero effort and worker $i$ exerts effort of $e_{i}=e_{i}^{C}=e_{j}+\frac{w_{i}-w_{j}}{c}=$ $\frac{w_{i}-w_{j}}{c}$.

The other corner solution obtains for high values of $\beta$, i.e., high disutility from advantageous inequality. In case of equal wages, an individual worker will not increase effort from a common intermediate effort level because she would suffer from disadvantageous inequality relative to her coworker who does not deviate (recall that $\alpha \geq \bar{\alpha}$ in case (iii)). By increasing their effort levels jointly, workers avoid this envy cost while reducing compassion cost relative to the firm. The only surviving equilibrium entails maximum effort $e^{F}$ for both workers. Again, the situation is slightly more complicated in case of unequal wages because payoff equalization then implies that the worker with the lower wage provides a lower effort level than $e_{j}^{F}$. With unequal wages, the worker who receives the higher wage (worker $i$ ) will provide $e_{i}=e_{i}^{F}$, while the low paid worker will provide $e_{j}=e_{j}^{C}=e_{i}-\frac{w_{i}-w_{j}}{c}$.

Which corner solution prevails depends on the value of $\beta$. Since now we are considering deviations where both workers coordinate on an effort level that equalizes their payoffs, non-pecuniary disutility from worker-worker inequality vanishes from the equation. Suppose both workers provide an intermediate amount of effort. For each worker, an increase in the effort level by one unit entails a cost increase by $c$ units and an increase in non-pecuniary utility by $\frac{\beta}{2}(c+v)$. Therefore, if $\frac{\beta}{2}(c+v)$ exceeds $c$, both workers will coordinate on an effort increase. If, instead, $c$ exceeds $\frac{\beta}{2}(c+v)$, they will coordinate on an effort reduction. Therefore, the threshold value for $\beta$ that divides the two cases is given by

$$
\frac{2 c}{c+v} \equiv \bar{\beta}
$$


We can now describe the two coalition-proof Nash Equilibria. In case (iii.a), workers care only to some degree about advantageous inequity (i.e., $\underline{\beta} \leq \beta<\bar{\beta}$ ); thus, they equalize payoffs with each other but they are not willing to reduce the payoff advantage relative to the firm. As a result, they jointly reduce effort until the low paid worker provides the minimal effort. In case (iii.b), workers suffer strongly under advantageous inequity $(\beta \geq \bar{\beta})$; they therefore equalize payoffs with each other and jointly increase their effort until the high paid worker chooses $e_{i}^{F}$.
(iii.a) $\alpha \geq \bar{\alpha}, \underline{\beta} \leq \beta<\bar{\beta}$ :
$e_{i}^{*}=\frac{w_{i}-w_{j}}{c} \geq 0, e_{j}^{*}=0$
(iii.b) $\alpha \geq \bar{\alpha}, \beta \geq \bar{\beta}$ :
$e_{i}^{*}=e_{i}^{F}, e_{j}^{*}=e_{i}^{*}-\frac{w_{i}-w_{j}}{c} \leq e_{j}^{F}$

\section{The Response of Inequity Averse Workers to Wage Cuts}

How do inequity averse workers respond to wage cuts? And how does their response depend on the wages paid to their coworkers? Suppose that wages can take on two levels, either high $\left(w_{i}=H\right)$ or low $\left(w_{i}=L\right.$ with $\left.H-L \equiv \Delta>0\right)$. Consider first the baseline treatment $\mathrm{HH}$ where both workers receive the high wage in the post-intervention phase. In cases (i) and (iii.a), they both provide the minimal effort (i.e., $e_{i}^{*}=e_{j}^{*}=0$ ) while they both exert effort that removes inequality between the firm and the workers in cases (ii) and (iii.b): $e_{i}^{*}=e_{j}^{*}=e_{H}^{F}=\frac{2}{c+v} H$.

Consider now the control treatment LL where both workers receive the low wage in the post-intervention phase. Because they both earn the same wage, this situation is analogous to the situation in which they both receive the high wage. Thus, in cases (i) and (iii.a), both workers provide the minimal effort (i.e., $e_{i}^{*}=e_{j}^{*}=0$ ) and in cases (ii) and (iii.b), they both provide $e^{F}$. However, $e^{F}$ is proportional to the wage, meaning that a lower wage implies a lower effort (i.e., $e_{L}^{F}=e_{H}^{F}-\frac{2 \Delta}{c+v}<e_{H}^{F}$ ). 
Finally, consider the main treatment $\mathrm{HL}$ where worker $i$ receives the high wage and worker $j$ receives the low wage. In case (i), the workers do not suffer much from a payoff advantage relative to the firm; thus, they both provide the minimal effort (i.e., $e_{i}^{*}=e_{j}^{*}=$ $0)$. In principle, the low paid worker may suffer from receiving less than her coworker; however, since she already provides the minimal effort she cannot withdraw further effort in order to reduce the payoff disadvantage relative to her coworker. In case (ii), the workers suffer much from their payoff advantage relative to the firm, implying that they both exert $e_{k}^{F}$. Thus, the high paid worker provides $e_{H}^{F}$ and the low paid worker provides $e_{L}^{F}<e_{H}^{F}$. Although the low paid worker receives a lower payoff than her coworker in this case, she is not willing to reduce this inequality because it would generate a large payoff advantage relative to the firm. The high paid worker is also not willing to reduce the payoff advantage relative to her coworker because it is never optimal to exert more than $e^{F}$.

In cases (iii.a) and (iii.b), workers generally equalize payoffs among themselves by choosing $e_{k}^{C}$. The workers in case (iii.a) suffer only to some extent from their payoff advantage relative to the firm $(\beta<\bar{\beta})$, implying that both of them would like to put in the lowest possible effort. However, only the low paid worker actually provides the minimal effort because the high paid worker would otherwise suffer from receiving more than both the firm and her coworker. Thus, the high paid worker equalizes payoffs with her coworker by providing more than minimal effort $e_{i}^{*}=\frac{\Delta}{c}$, unless this effort level exceeds $\mathrm{e}_{\mathrm{H}}^{\mathrm{F}}$, in which case she chooses $e_{H}^{F}$. The workers in case (iii.b) suffer strongly under the payoff advantage relative to the firm $(\beta>\bar{\beta})$. The high paid worker therefore provides $e_{H}^{F}$. Because workers also suffer much from payoff disadvantages (i.e., $\alpha \geq \bar{\alpha}$ ) in this case, the low paid worker prefers equalizing payoffs with her coworker rather than with the firm in order to prevent her from receiving less than her coworker. Hence, the low paid worker chooses $e_{j}^{*}=e_{H}^{F}-$ $\frac{\Delta}{c}$ unless this value is negative, in which case she chooses the minimal effort (i.e., $e_{j}^{*}=0$ ). Thus, the low paid worker in case (iii.b) provides effort $e_{H}^{F}-\frac{\Delta}{c}$ in the HL treatment, whereas both low paid workers provide effort $e_{L}^{F}=e_{H}^{F}-\frac{2 \Delta}{c+v}$ in the LL treatment. This means that the low paid workers in HL provide a lower effort than workers in LL because $\frac{\Delta}{c}>\frac{2 \Delta}{c+v}$. 
Now we can derive the hypotheses for the change in effort from pre- to postintervention phase across treatments:

\section{Hypothesis (H1): Treatment LL}

(1a) If $\beta<\underline{\beta}$ or $\alpha \geq \bar{\alpha}, \beta<\bar{\beta}$ : both workers' equilibrium effort remains the same.

(1b) Otherwise: both workers' equilibrium effort decreases.

\section{Hypothesis (H2): Group HL2}

(2a) If $\beta<\underline{\beta}$ or $\alpha \geq \bar{\alpha}, \beta<\bar{\beta}$ : worker 2's equilibrium effort remains the same.

(2b) Otherwise, worker 2's equilibrium effort decreases.

$\left(2 b^{\prime}\right)$ If $\alpha<\bar{\alpha}, \beta \geq \underline{\beta}$ : worker 2's equilibrium effort is the same as in LL.

(2b") If $\alpha \geq \bar{\alpha}, \beta \geq \bar{\beta}$ : worker 2's equilibrium effort is lower than in LL.

\section{Hypothesis (H3): Group HL1}

(3a) If $\alpha \geq \bar{\alpha}, \underline{\beta} \leq \beta<\bar{\beta}$ worker 1's equilibrium effort increases.

(3b) Otherwise, worker 1's equilibrium effort remains the same. 


\section{References}

Abeler, J., A. Falk, L. Götte, and D. Huffman, "Reference Points and Effort Provision," American Economic Review, (forthcoming).

Agell, J., and P. Lundborg, "Theories of Pay and Unemployment: Survey Evidence from Swedish Manufacturing Firms," Scandinavian Journal of Economics, 97 (1995), 295-307.

Akerlof, G., and J. Yellen, "The Fair-Wage Effort Hypothesis and Unemployment," Quarterly Journal of Economics, 105 (1990), 255-283.

Babcock, L., and G. Loewenstein, "Explaining Bargaining Impasse: The Role of Self-Serving Biases," The Journal of Economic Perspectives, 11 (1997), 109-126.

Barberis, N., M. Huang, and R. Thaler, "Individual Preferences, Monetary Gambles, and Stock Market Participation: A Case for Narrow Framing," The American economic review, 96 (2006), 1069-1090.

Baron, J., and D. Kreps, Strategic Human Resources: Frameworks for General Managers (John Wiley New York, 1999).

Bartling, B., and F. Von Siemens, "The Intensity of Incentives in Firms and Markets: Moral Hazard with Envious Agents," Labour Economics, (2009).

Bernheim, B., B. Peleg, and M. Whinston, "Coalition-Proof Nash Equilibria I. Concepts," Journal of Economic Theory, 42 (1987), 1-12.

Bewley, T. F., "Why Not Cut Pay?," European Economic Review, 42 (1998), 459-490.

Bewley, T. F., Why Wages Don't Fall During a Recession (Cambridge: Harvard University Press, 1999).

Blinder, A. S., and D. H. Choi, "A Shred of Evidence on Theories of Wage Stickiness," The Quarterly Journal of Economics, 105 (1990), 1003-1015.

Bolton, G., and A. Ockenfels, "Erc: A Theory of Equity, Reciprocity, and Competition," American Economic Review, 90 (2000), 166-193.

Brandts, J., and G. Charness, "Do Labour Market Conditions Affect Gift Exchange? Some Experimental Evidence," Economic Journal, 114 (2004), 684-708.

Camerer, C., L. Babcock, G. Loewenstein, and R. Thaler, "Labor Supply of New York City Cabdrivers: One Day at a Time," Quarterly Journal of Economics, 112 (1997), 407-441.

Camerer, C., and U. Malmendier, "Behavioral Economics of Organizations," in Behavioral Economics and Its Applications, (Princeton and Oxford: Princeton University Press, 2007).

Campbell, C. M., and K. S. Kamlani, "The Reasons for Wage Rigidity: Evidence from a Survey of Firms," The Quarterly Journal of Economics, 112 (1997), 759-789.

Card, D., "Deregulation and Labor Earnings in the Airline Industry," in Regulatory Reform and Labor Markets., In James Peoples, ed. (Norwell, MA: Kluwer Academic Publishers, 1997).

Card, D., A. Mas, E. Moretti, and E. Saez, "Inequality at Work: The Effect of Peer Salaries on Job Satisfaction," NBER Working Paper 16396, (2010).

Charness, G., "Responsibility and Effort in an Experimental Labor Market," Journal of Economic Behavior \& Organization, 42 (2000), 375-384. 
Charness, G., G. R. Frechette, and J. H. Kagel, "How Robust Is Laboratory Gift Exchange?," Experimental Economics, 7 (2004), 189-205.

Charness, G., and P. Kuhn, "Does Pay Inequality Affect Worker Effort? Experimental Evidence," Journal of Labor Economics, 25 (2007), 693-723.

Clark, A., D. Masclet, and M.-C. Villeval, "Effort and Comparison Income: Experimental and Survey Evidence," Industrial and Labor Relations Review, 63 (2010).

Clark, A., and C. Senik, "Who Compares to Whom? The Anatomy of Income Comparisons in Europe," The Economic Journal, 120 (2010), 573-594.

Cohn, A., E. Fehr, and L. Goette, "Fair Wages and Effort: Evidence from a Field Experiment," IEW Working Paper, University of Zurich, 2009.

Cooper, D., and J. Kagel, "Other Regarding Preferences: A Selective Survey of Experimental Results," Handbook of Experimental Economics, 2 (2009).

Cox, J., D. Friedman, and S. Gjerstad, "A Tractable Model of Reciprocity and Fairness," Games and Economic Behavior, 59 (2007), 17-45.

Dufwenberg, M., and G. Kirchsteiger, "A Theory of Sequential Reciprocity," Games and Economic Behavior, 47 (2004), 268-298.

Falk, A., E. Fehr, and C. Zehnder, "Fairness Perceptions and Reservation Wages-the Behavioral Effects of Minimum Wage Laws," The Quarterly Journal of Economics, 121 (2006), 1347-1381.

Falk, A., and U. Fischbacher, "A Theory of Reciprocity," Games and Economic Behavior, 54 (2006), 293-315.

Falk, A., and J. Heckman, "Lab Experiments Are a Major Source of Knowledge in the Social Sciences," Science, 326 (2009), 535.

Falk, A., and M. Knell, "Choosing the Joneses: Endogenous Goals and Reference Standards," Scandinavian Journal of Economics, 106 (2004), 417-435.

Farber, H. S., "Is Tomorrow Another Day? The Labor Supply of New York City Cabdrivers," Journal of Political Economy, 113 (2005), 46-82.

Fehr, E., and A. Falk, "Wage Rigidity in a Competitive Incomplete Contract Market," The Journal of Political Economy, 107 (1999), 106-134.

Fehr, E., and L. Goette, "Do Workers Work More If Wages Are High? Evidence from a Randomized Field Experiment," The American Economic Review, 97 (2007), 298-317.

Fehr, E., G. Kirchsteiger, and A. Riedl, "Does Fairness Prevent Market Clearing? An Experimental Investigation," The Quarterly Journal of Economics, 108 (1993), 437-460.

Fehr, E., and K. M. Schmidt, "A Theory of Fairness, Competition, and Cooperation," Quarterly Journal of Economics, 114 (1999), 817-868.

Frank, R., "Are Workers Paid Their Marginal Products?," The American economic review, 74 (1984), 549-571.

Gneezy, U., and J. List, "Putting Behavioral Economics to Work: Field Evidence of Gift Exchange," Econometrica, 74 (2006), 1365-1384.

Greenberg, J., C. E. Ashton-James, and N. M. Ashkanasy, "Social Comparison Processes in Organizations," Organizational Behavior and Human Decision Processes, 102 (2007), 22-41. 
Hannan, R. L., J. H. Kagel, and D. V. Moser, "Partial Gift Exchange in an Experimental Labor Market: Impact of Subject Population Differences, Productivity Differences, and Effort Requests on Beha," Journal of Labor Economics, 20 (2002), 923-951.

Hennig-Schmidt, H., B. Rockenbach, and A. Sadrieh, "In Search of Workers' Real Effort Reciprocity-a Field and a Laboratory Experiment," Journal of the European Economic Association, 8 (2010), 817-837.

Hicks, J., The Theory of Wages (London: Macmillan, 1932).

Holmström, B., and J. Roberts, "The Boundaries of the Firm Revisited," The Journal of Economic Perspectives, 12 (1998), 73-94.

Kochan, T., and T. Barocci, Human Resource Management and Industrial Relations: Text, Readings, and Cases (Boston: Little, Brown, 1985).

Kole, S., and K. Lehn, "Workforce Integration and the Dissipation of Value in Mergers," Mergers and productivity, (2000), 239.

Krueger, A. B., and A. Mas, "Strikes, Scabs, and Tread Separations: Labor Strife and the Production of Defective Bridgestone/Firestone Tires," Journal of Political Economy, 112 (2004), 253-289.

Kube, S., M. Maréchal, and C. Puppe, "The Currency of Reciprocity-Gift-Exchange in the Workplace," IEW Working Paper, University of Zurich Working Paper No. 377, 2010a.

Kube, S., M. Maréchal, and C. Puppe, "Do Wage Cuts Damage Work Morale? Evidence from a Natural Field Experiment," IEW Working Paper, University of Zurich Working Paper No. 471, 2010b.

Levine, D. I., "What Do Wages Buy?," Administrative Science Quarterly, 38 (1993), 462-483.

List, J. A., "The Behavioralist Meets the Market: Measuring Social Preferences and Reputation Effects in Actual Transactions," Journal of Political Economy, 1141 (2006), 1-37.

List, J. A., "Homo Experimentalis Evolves " Science, 321 (2008), 207-208.

Marshall, A., Principles of Economics (London: Macmillan, 1890).

Mas, A., "Pay, Reference Points, and Police Performance," The Quarterly Journal of Economics, 121 (2006), 783-821.

Mas, A., "Labor Unrest and the Quality of Production: Evidence from the Construction Equipment Resale Market," Review of Economic Studies, 75 (2008), 229-258.

Mas, A., and E. Moretti, "Peers at Work," The American Economic Review, 99 (2009), 112-145.

Nickerson, J. A., and T. R. Zenger, "Envy, Comparison Costs, and the Economic Theory of the Firm," Strategic Management Journal, 29 (2008), 1429-1449.

Oettinger, G., "An Empirical Analysis of the Daily Labor Supply of Stadium Vendors," Journal of Political Economy, 107 (1999), 360-392.

Pfeffer, J., and N. Langton, "The Effect of Wage Dispersion on Satisfaction, Productivity, and Working Collaboratively: Evidence from College and University Faculty," Administrative Science Quarterly, (1993), 382-407.

Rabin, M., "Incorporating Fairness into Game Theory and Economics," American Economic Review, 83 (1993), 1281-1302. 
Rabin, M., and G. Weizsacker, "Narrow Bracketing and Dominated Choices," The American economic review, 99 (2009), 1508-1543.

Shapiro, C., and J. E. Stiglitz, "Equilibrium Unemployment as a Worker Discipline Device," The American Economic Review, 74 (1984), 433-444.

Shearer, B., "Piece Rates, Fixed Wages and Incentives: Evidence from a Field Experiment," Review of Economic Studies, 71 (2004), 513-534.

Slichter, S., "Industrial Morale," The Quarterly Journal of Economics, 35 (1920), 36-60.

Thöni, C., and S. Gächter, "Social Comparison and Performance: Experimental Evidence on the Fair WageEffort Hypothesis," Journal of Economic Behavior \& Organization, (forthcoming). 


\section{Tables and Figures}

Table [1]: Hourly wages (in €)

\begin{tabular}{lcccccc}
\hline $\begin{array}{l}\text { Treatment } \\
\text { Group }\end{array}$ & \multicolumn{2}{c}{ HH } & \multicolumn{2}{c}{ LL } & \multicolumn{2}{c}{ HL } \\
& Worker 1 & Worker 2 & Worker 1 & Worker 2 & Worker 1 & Worker 2 \\
\hline Pre-intervention & 12 & 12 & 12 & 12 & 12 & 12 \\
Post-intervention & 12 & 12 & 9 & 9 & 12 & 9 \\
\hline
\end{tabular}

Table [2]: Descriptive statistics

\begin{tabular}{lrrrrr}
\hline $\begin{array}{l}\text { Treatment } \\
\text { Group }\end{array}$ & HH & LL & & HL & Total \\
\hline Workers (\#) & & & HL1 & HL2 & \\
Female (\#) & 24 & 24 & 24 & 24 & 96 \\
Age (mean) & 18 & 18 & 19 & 19 & 74 \\
Reported sick (\#) & 20.5 & 21.2 & 20.2 & 21.1 & 20.7 \\
Cards sold per shift (mean) & 1 & 1 & 0 & 1 & 3 \\
$\quad$ Pre-intervention & & & & & \\
$\quad$ Post-intervention & 20.8 & 22.4 & 24.3 & 22.0 & 22.4 \\
$\quad$ Overall & 22.8 & 21.4 & 26.5 & 18.4 & 22.3 \\
\hline
\end{tabular}


Table [3]: OLS regressions of treatment effects on individual work performance

\begin{tabular}{|c|c|c|}
\hline Dependent variable: $\log ($ cards sold) & (1) & $(2)$ \\
\hline Post-intervention & $\begin{array}{c}0.058 \\
(0.080)\end{array}$ & $\begin{array}{c}0.090 \\
(0.074)\end{array}$ \\
\hline LL x Post-intervention & $\begin{array}{l}-0.106 \\
(0.090)\end{array}$ & $\begin{array}{l}-0.145^{*} \\
(0.079)\end{array}$ \\
\hline HL1 x Post-intervention & $\begin{array}{c}0.034 \\
(0.095)\end{array}$ & $\begin{array}{c}0.015 \\
(0.089)\end{array}$ \\
\hline HL2 x Post-intervention & $\begin{array}{c}-0.306 * * * \\
(0.103)\end{array}$ & $\begin{array}{c}-0.342 * * * \\
(0.101)\end{array}$ \\
\hline Demand potential & & $\begin{array}{c}0.117^{* * *} \\
(0.034)\end{array}$ \\
\hline Constant $^{16}$ & $\begin{array}{c}3.057^{* * *} \\
(0.015)\end{array}$ & $\begin{array}{c}3.048 * * * \\
(0.015)\end{array}$ \\
\hline Individual Fixed Effects & Yes & Yes \\
\hline $\begin{array}{l}N \\
\text { Adj. } R^{2}\end{array}$ & $\begin{array}{c}189 \\
0.202\end{array}$ & $\begin{array}{c}179 \\
0.312\end{array}$ \\
\hline
\end{tabular}

Standard errors, clustered over teams, in parentheses.

${ }^{*} p<0.10,{ }^{* *} p<0.05,{ }^{* * *} p<0.01$ according to two-sided t-tests

${ }^{16}$ The constant captures the logarithmic average performance in the pre-intervention phase. 
Figure [1]: Average treatment effects on individual work performance
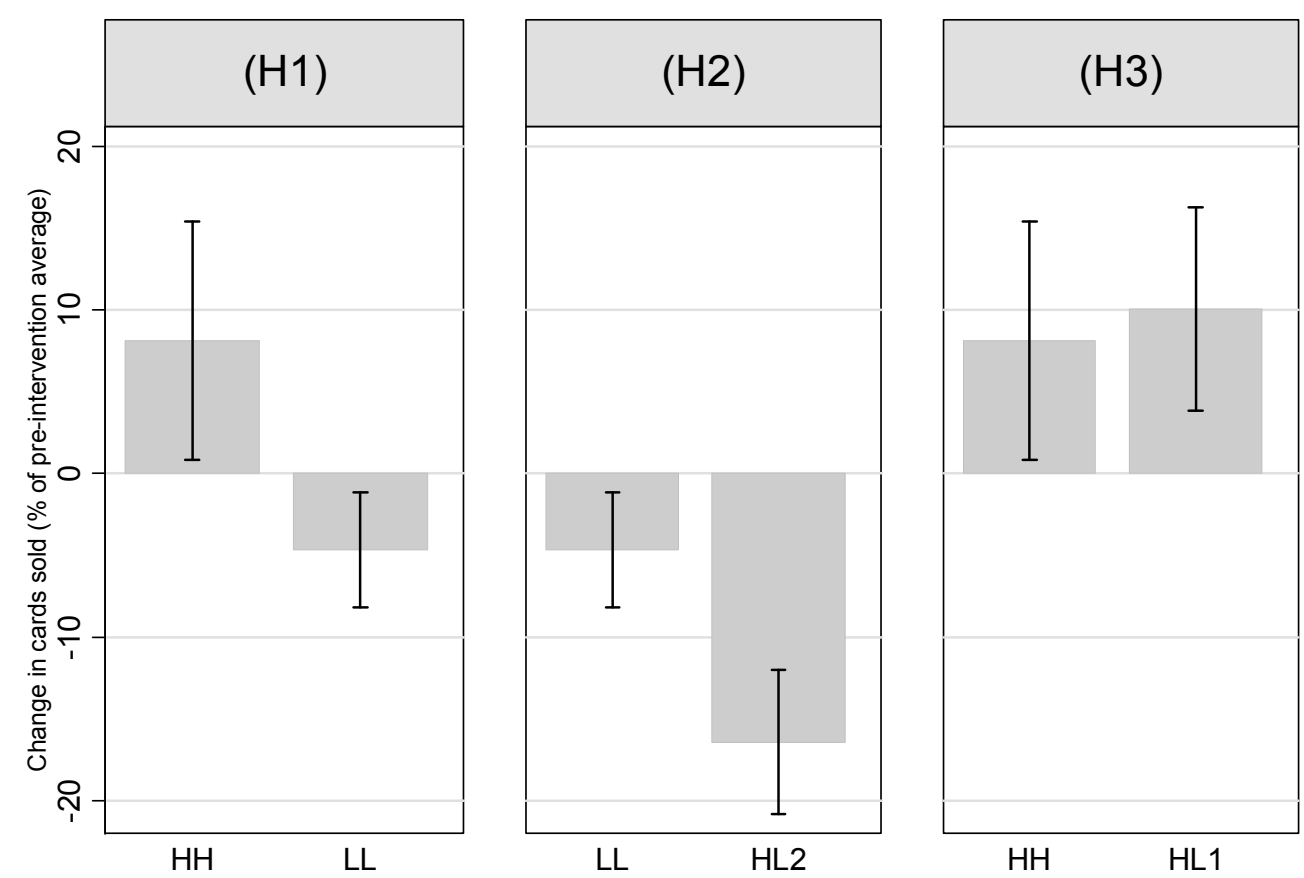

(error bars represent standard error of the mean; spare workers excluded)

Panel (H1): Performance changes in treatment HH (baseline) and LL (general wage cut).

Panel (H2): Performance changes in treatment LL (general wage cut) and HL2 (unilateral wage cut).

Panel (H3): Performance changes in treatment HH (baseline) and HL1 (spared workers in the unilateral wage cut treatment). 